\title{
Prediction of Springback in the Air Bending Process Using a Kriging Metamodel
}

\author{
Fayiz Abu Khadra \\ Faculty of Eng.-Rabigh, \\ King Abdulaziz University \\ Saudi Arabia \\ fabukhadra@kau.edu.sa
}

\author{
Abdel-Wahab El-Morsy \\ Faculty of Eng.-Rabigh, King Abdulaziz University, \\ Saudi Arabia and Faculty of Eng.-Helwan, Helwan \\ University, Egypt \\ aalmursi@kau.edu.sa
}

\begin{abstract}
This paper addresses the use of the kriging approach to predict the springback in the air bending process. The materials and the geometrical parameters, which significantly affect the springback, were considered as inputs, and the springback angle was considered as the response. A verified nonlinear finite element model was used to generate the training data required to create the kriging metamodel. The training examples were selected based on computer-generated D-optimal designs. A comparison between the kriging approaches and the response surface methodology is conducted and discussed. The results showed that kriging accurately predicts the finite element springback results. Comparing the accuracy of kriging with a response surface methodology shows that kriging with a 2 nd degree polynomial and exponential correlation function predicts the springback more accurately than the response surface methodology.
\end{abstract}

Keywords-Metamodels; Springback; Kriging; Response Surface Methodology; D-Optimal Designs

\section{INTRODUCTION}

Springback is a common phenomenon that occurs in sheet metal bending after unloading the static loads due to elastic recovery. In recent years, numerous investigations have been conducted on the springback phenomenon in sheet metal bending processes via experimental [1-5], analytical [6-9], and numerical [10-12] methods for different shapes, processes and material parameters. Many types of geometries have been performed to predict the springback, including pure/air bending [4, 10, 13], V-bending [1, 14-15], U-bending [16-19], Lbending [7, 20-21], draw-bending [2-3, 6], beams subjected to repeated bending [5], and tube bending [22]

A number of analytical models based on the geometry and the material characteristics have been conducted using the analytical methods for springback predictions. The recent approaches to analytical solutions include the prediction of springback considering Young's modulus variation with a piecewise hardening function [23], friction modeling of high strength steels [24-25], semi-analytical modeling of springback [26], U-bending as a function of stress distribution in the thickness of sheet metal [27], springback prediction of an asymmetric thin-walled tube [28], and an analytical springback model for lightweight hexagonal close-packed sheet [29]. In general, most of the analytical models assume a simplified process and material properties due to the complexity of the problem.

The finite element method is a powerful tool for analyzing sheet bending processes with various materials and test conditions [1, 11, 30-32]. Because a large number of FEMs is required to develop an accurate approximation for springback prediction, it is not practical, relatively time-consuming, and computationally expensive to apply it for a complex process, such as metal forming. In addition, a direct link between finite element code and optimization routines can lead to inefficient results because a large number of iterative calls are required during the optimization. Recently, there has been a great increase in the application of metamodels instead of the complex analytics models that are limited by assumptions [3334]. Several metamodeling techniques with various degrees of complexity have been extensively applied, such as the response surface methodology [35-38], artificial neural network [39-42], radial basis function [43-45], and kriging [46-49]. Some of these techniques are suitable for global approximations, i.e., can be used for representing the complete design space, while others are more suitable for local approximations of a part of the design space. The existing studies to predict springback in the air bending process mostly use training data from experiments with real-life systems. Consequently, these studies considered only inadequate materials and tool geometry [37, $39-41,50]$.

In this study, the kriging approach is developed to predict springback in the air bending process. The finite element simulation is employed to generate the training data required to train the kriging metamodel. The use of a finite element analysis permits the mapping of a large range of materials and geometrical tool dimensions. The kriging metamodel is compared with the traditional response surface methodology (RSM) to show the merits of the kriging metamodel to predict springback.

\section{Metamodel generation}

A metamodel [46] is a mathematical approximation of a computationally expensive numerical model. Using a metamodel, one can study the behavior of the response 
function more efficiently and can perform an optimization very rapidly. The mathematical approximation can be written as:

$$
y=f(x) \cong g(x)
$$

where $f(x)$ is the simulation model function, and $g(x)$ is the metamodel approximation to $y$, which maps the design variables $X$ to the predicted response $\hat{Y}$.The predicted response $\hat{Y}$ will differ from the observed response y from the simulation model.

$$
y=\widehat{Y}+\varepsilon
$$

where the error $\varepsilon$ represents the approximation error. To build a metamodel, $n$ runs of the simulation model with different variable settings $X_{i}=\left(X_{1}, X_{2}, \ldots \ldots, X_{n}\right)$ and the $k$ design variables are required.

\section{A. Response surface methodology}

RSM [35] is a set of mathematical methods for enhancing processes and products. The relationship between the response $(y)$ and the vector independent factors $(x)$ can be expressed by:

$$
y=f(x)+\varepsilon
$$

where $\varepsilon$ is the random error, which is expected to be normally and independently distributed with a mean of zero and a standard deviation $\sigma$. The broadly used RSM functions are loworder polynomials and can be expressed as:

$$
y=\beta_{0}+\sum_{i=1}^{k} \beta_{i} x_{i}
$$

For considerable curvature, a second-order polynomial can be expressed as:

$$
y=\beta_{0}+\sum_{i=1}^{k} \beta_{i} x_{i}+\sum_{i<j} \sum \beta_{i j} x_{i} x_{j}+\sum_{i=1}^{k} \beta_{i i} x_{i}^{2}
$$

The parameters in (4) and (5) are typically determined by a least squares regression analysis. The least squares estimators of the regression coefficients $\beta$ are denoted by $\widehat{\beta}$. The regression model may be written as:

$$
y=X \beta+\varepsilon
$$

Thus, $Y$ is a vector of $n$ responses, $X$ is an $n \times p$ design matrix consisting of variable settings, $\beta$ is a vector of $p$ regression variables and $\varepsilon$ is a vector of the $n$ errors. In the design matrix, each row corresponds to one design point, and each column corresponds to one regression coefficient. The fitted regression model becomes:

$$
\widehat{Y}=X \widehat{\beta}
$$

Assuming that $\beta$ has a zero mean and a variance-covariance matrix given by $\sigma^{2} I_{n}$, the so-called ordinary least-squares estimator of $\beta$ is [38]:

$$
\widehat{\beta}=\left(X^{T} X\right)^{-1} X^{T} y
$$

the variance-covariance matrix of $\widehat{\beta}$ is then of the form

$$
\operatorname{Var}(\widehat{\beta})=\sigma^{2}\left(X^{T} X\right)^{-1}
$$

\section{B. Kriging metamodel}

The kriging interpolation method [47], developed in the field of spatial statistics and geo-statistics, has been widely used in recent years to model deterministic simulations. Kriging predicts the value of a new point using stochastic processes. Kriging consists of a combination of a known polynomial plus fitting errors, as shown in 10:

$$
Y(x)=\mathrm{f}^{T}(x) \beta+Z(x)
$$

where $\mathrm{Y}(\mathrm{x})$ is the unknown response of interest, $f(x)=\left[f_{1}(x), f_{2}(x), \ldots, f_{p}(x)\right]^{T}$ is the $(P \times 1)$ vector of regression functions, and $\beta=\left[\beta_{1}, \beta_{2}, \ldots, \beta_{p}\right]^{T}$ is the $(\mathrm{P} \times 1)$ vector of unknown coefficients. $\mathrm{f}^{\mathrm{T}}(\mathrm{x}) \boldsymbol{\beta}$ globally approximates the design space. In many cases, $\mathrm{f}^{\mathrm{T}}(\mathrm{x}) \boldsymbol{\beta}$ is assumed to be a constant (ordinary kriging), or it may be a first-order or second-order polynomial. " $Z(x)$ " is a stochastic process, which has a mean of zero, variance of $\sigma_{2}$, and the following covariance matrix:

$$
\operatorname{cov}\left[Z\left(S^{i}\right), Z\left(S^{j}\right)\right]=\sigma^{2} R\left(\left[R\left(S^{i}, S^{j}\right]\right)\right.
$$

$Z(X)$ performs localized deviations, so that the kriging model interpolates $n_{s}$ sampled data. The correlation matrix $R$ is $n_{s} \times n_{s}$ is symmetric with ones along the diagonal. [R( $\left(S^{i}, S^{j}\right)$ ] is a user-defined correlation function. The selection of the correlation function determines on how to fit the data. In this study, the most popular correlation function is Gaussian, in which the exponent 2 is used in (12).

$$
R\left(S^{i}, S^{j}\right)=\exp \left[-\sum_{k=1}^{n} \theta_{k}\left|S_{k}^{i}-S_{k}^{j}\right|\right]
$$

The quantities $S_{k}^{i}$ and $S_{k}^{j}$ are the $k_{\text {th }}$ components of the sampled points $S_{i}$ and $S_{j}$, respectively. As part of the kriging approximation, the unknown $\theta_{\mathrm{k}}$ terms are determined. The maximum likelihood estimation of $\theta_{\mathrm{k}}$ can be calculated by maximizing the following expression:

$$
\max _{\theta>0} \frac{-\left[n s \ln \left(\hat{\sigma}_{Z}^{2}\right)+\ln |R|\right]}{2}
$$

$\widehat{\sigma}_{Z}^{2}$ is the estimated process variance and can be calculated by:

$$
\widehat{\sigma}_{Z}^{2}=\frac{(Y-F \widehat{\beta})^{T} R^{-1}(Y-F \widehat{\beta})}{n_{s}}
$$

The kriging estimate at any untried point $\mathrm{x}$ is given by:

$$
\widehat{\mathrm{Y}}(\mathrm{X})=\mathrm{f}^{\mathrm{T}}(\mathrm{x}) \widehat{\beta}+\mathrm{r}^{\mathrm{T}}(\mathrm{x}) \mathrm{R}^{-1}(\mathrm{Y}-\mathrm{F} \widehat{\beta})
$$




$$
\begin{gathered}
\widehat{\beta}=\left(F^{\mathrm{T}} R^{-1} F\right)^{-1} F^{\mathrm{T}} R^{-1} Y \\
F=\left[f\left(S^{1}\right), f\left(S^{2}\right), \ldots . ., f\left(S^{n_{s}}\right)\right]^{T}
\end{gathered}
$$

$\mathrm{F}$ is a column vector with $\mathrm{n}_{\mathrm{s}}$ components, which is filled with ones when $p(x)$ is a constant. $\left.\mathrm{Y}=\left[\mathrm{y}_{\mathrm{s}^{1}}, \mathrm{y}_{\mathrm{s}^{2}}, \ldots . \mathrm{y}_{\mathrm{s}^{\mathrm{ns}}}\right)\right]$ is the column vector of length $n_{s}$, which contains the response values at each sampled point.

\section{METHODOLOGY OF SPRINGBACK PREDICTION USING A KRIGING METAMODEL}

The procedure to predict springback in the air bending process consists of the following phases. A schematic representation of the methodology for springback angle prediction using a kriging metamodel is shown in Figure 1.

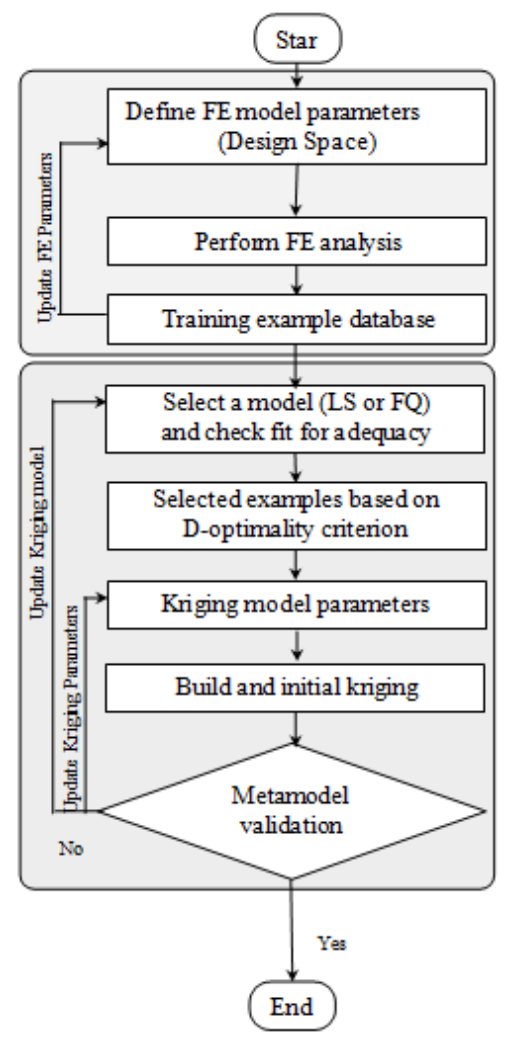

Fig. 1. Flowchart of the methodology for springback prediction using kriging metamodel.

\section{A. Identify the design space and select the design variables}

The first step is to select the design variables $\left(\mathrm{E}, \sigma_{\mathrm{y}}, \mathrm{K}, \mathrm{n}, \mathrm{t}\right.$, $\left.R_{p}, R_{d}, W_{d}, \theta_{1}\right)$, which is a very important step for generating accurate models (Table I). The method for selecting the sample points, which is dependent on the design variables, is called the design of experiments (DOE). These sample points are used as the input variables for the next step. In this study, the Doptimality experimental design criterion [51] was used to sample the design space. D-optimality is the most common criterion, which seeks to maximize $\left|X^{T} X\right|$, the determinant of the information matrix $\left(X^{T} X\right)$ of the design. Equation 18 shows the selection of $X^{T}$ out of all possible design matrices chosen from $\xi_{\mathrm{n}}$.

$$
\left|\mathrm{X}^{\mathrm{T}} \mathrm{X}\right|=\max _{\xi_{n}=N}\left(\left|X^{T} X\right|\right)
$$

Maximizing the determinant of the information matrix $\left(X^{T} X\right)$ is equivalent to minimizing the determinant of the dispersion matrix $\left(X^{T} X\right)^{-1}$.

$$
\left|X^{\mathrm{T}} X\right|=\frac{1}{\left|\left(X^{\mathrm{T}} \mathrm{X}\right)^{-1}\right|}
$$

TABLE I. THE DESIGN SPACE CONSIDERED IN THIS STUDY

\begin{tabular}{|c|c|c|c|c|c|c|c|c|c|}
\hline \multicolumn{4}{|c|}{ Material Parameters } & \multicolumn{4}{c|}{ Geometric Parameters } \\
\hline $\begin{array}{c}\text { Input } \\
\text { parameter }\end{array}$ & $\begin{array}{c}\mathrm{E} \\
\mathrm{GPa}\end{array}$ & $\begin{array}{c}\sigma_{\mathrm{y}} \\
\mathrm{MPa}\end{array}$ & $\begin{array}{c}\mathrm{K} \\
\mathrm{MPa}\end{array}$ & $\mathrm{n}$ & $\begin{array}{c}\mathrm{t} \\
\mathrm{mm}\end{array}$ & $\begin{array}{c}\mathrm{R}_{\mathrm{p}} \\
\mathrm{mm}\end{array}$ & $\begin{array}{c}\mathrm{R}_{\mathrm{d}} \\
\mathrm{mm}\end{array}$ & $\begin{array}{c}\mathrm{W}_{\mathrm{d}} \\
\mathrm{mm}\end{array}$ & $\begin{array}{c}\theta_{1} \\
\mathbf{(}^{\mathbf{9}}\end{array}$ \\
\hline Maximum & 210 & 525 & 1585.4 & 0.48 & 6 & 20 & 20 & 100 & 126.9 \\
\hline Minimum & 67.34 & 60 & 164.12 & 0.06 & 1 & 2 & 1 & 40 & 53.22 \\
\hline
\end{tabular}

\section{B. Generate the training points using FE simulation}

The first step in generating the training points is to build an accurate FE model of the air bending process using the design space obtained from the previous stage. Figure 2 shows a schematic of FE model.

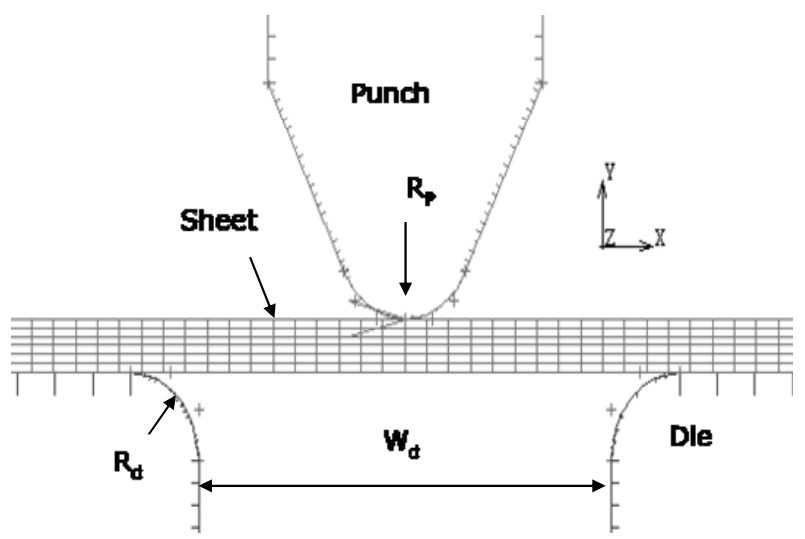

Fig. 2. Schematic diagram of the finite element model.

The material is assumed to be isotropic and homogeneous. The FE analysis is simplified to a 2D plane strain. A 4-node, iso-parametric, arbitrary quadrilateral plane-strain element is applied. This element uses bilinear interpolation functions by activation of the assumed strain formulation. The strain hardening is defined by Swift's Eq. which is given by:

$$
\bar{\sigma}=k\left(\varepsilon_{0}+\bar{\varepsilon}\right)^{n}
$$

The equivalent plastic stress $\bar{\sigma}$ is described by Swift's exponential hardening law, based on the material's consistency $K$, the equivalent plastic strain $\bar{\varepsilon}$, and the hardening exponent $n$. The input parameters influencing the amount of springback are the modulus of elasticity, the strain-hardening coefficient $n$, the yield strength $\sigma_{y}$, and the geometrical parameters. The geometrical parameters include 
the thickness of sheet $t$, radius of punch $R_{p}$, radius of die $R_{d}$, width of die $\mathrm{W}_{\mathrm{d}}$, and bending angle $\theta 1$. The developed metamodel can be represented by:

$$
\Delta \theta=\left(E, \sigma_{y}, K, n, t, R_{p}, R_{d}, W_{d}, \theta_{1}\right)
$$

\section{Metamodel building}

In this study, two metamodel techniques were used, KMM and RSM. Two training datasets were generated using the FE simulation stage. The first dataset is based on a linearinteractions (LI) model. A model for two variables can be given by:

$$
y=b_{0}+b_{1} X_{1}+b_{2} X_{2}+b_{12} X_{1} X_{2}
$$

The second dataset is based on the full quadratic (FQ) model. For example, a quadratic model for two variables is

$$
y=b_{0}+b_{1} X_{1}+b_{2} X_{2}+b_{12} X_{1} X_{2}+b_{11} X_{1}^{2}+b_{22} X_{2}^{2}
$$

For validation, the metamodels use a dataset, which is different from the above selected datasets to create the metamodels. The study was performed using a combination of selected datasets and different regression functions for kriging to find the best metamodel for the prediction of the springback angle in the air bending process. The results are presented for the following kriging metamodels:

- Kriging metamodel with a constant and an exponential correlation function $\left(\mathrm{P}_{\mathrm{EXP}}\right)$

- Kriging metamodel with a $1^{\text {st }}$-degree polynomial and an exponential correlation function ( $\left.\mathrm{P} 1_{\mathrm{EXP}}\right)$

- Kriging metamodel with a $2^{\text {nd }}$-degree polynomial and an exponential correlation function ( $\left.\mathrm{P} 2_{\mathrm{EXP}}\right)$

\section{Metamodel validation}

The accuracy of the metamodel is influenced by the metamodel type as well as the quality and quantity of the training dataset. The metamodels should be validated before being used as substitute models by comparing the metamodel results. In this study, useful means to determine the accuracy and the predictive capability of the metamodels are the normalized root-mean-squared error (NRMSE), the normalized maximum absolute error (NMAX), and the statistical correlation $\left(\mathrm{R}^{2}\right)$.

$$
\begin{aligned}
& R^{2}=1-\frac{\sum_{i=1}^{m}\left(Y_{i}-\widehat{Y}_{l}\right)^{2}}{\sum_{i=1}^{m}\left(Y_{i}-\bar{Y}_{l}\right)^{2}} \\
& \text { NRMSE }=\sqrt{\frac{\sum_{i=1}^{m}\left(Y_{i}-\hat{Y}_{1}\right)^{2}}{\sum_{i=1}^{m}\left(Y_{i}\right)^{2}}}
\end{aligned}
$$

$$
N M A X=\frac{\max \left|Y_{i}-\hat{Y}\right|}{\sqrt{\frac{1}{m} \sum_{i=1}^{m}\left(Y_{i}-\bar{Y}_{l}\right)^{2}}}
$$

where $\mathrm{Y}$ and $\hat{Y}$ are measured and predicted values. Additionally, $\hat{Y}$ is the mean of the actual function values at $m$ test points. The larger the $\mathrm{R}^{2}$, the more accurate the metamodel. The lower NRMSE and NMAX, the more accurate the metamodel. The $\mathrm{R}^{2}$ and the NRMSE provide a measure of the overall accuracy, while the NMAX is a measure of the local accuracy of the model. To provide a reliable accuracy, the validation set must be large enough and spread out over the design space.

\section{DISCUSSION OF THE RESULTS}

Figure 3 shows the training points that are space-filling for two factors, the yield strength and the bending angle before springback $\theta 1$. From the histogram figures, the improvement in the space filling capabilities can be observed when the FQ model is used. The selected design points are closely and uniformly distributed through the design space. Table II summarizes the coefficient of determination $\left(\mathrm{R}^{2}\right)$ for the full quadratic and linear interaction models
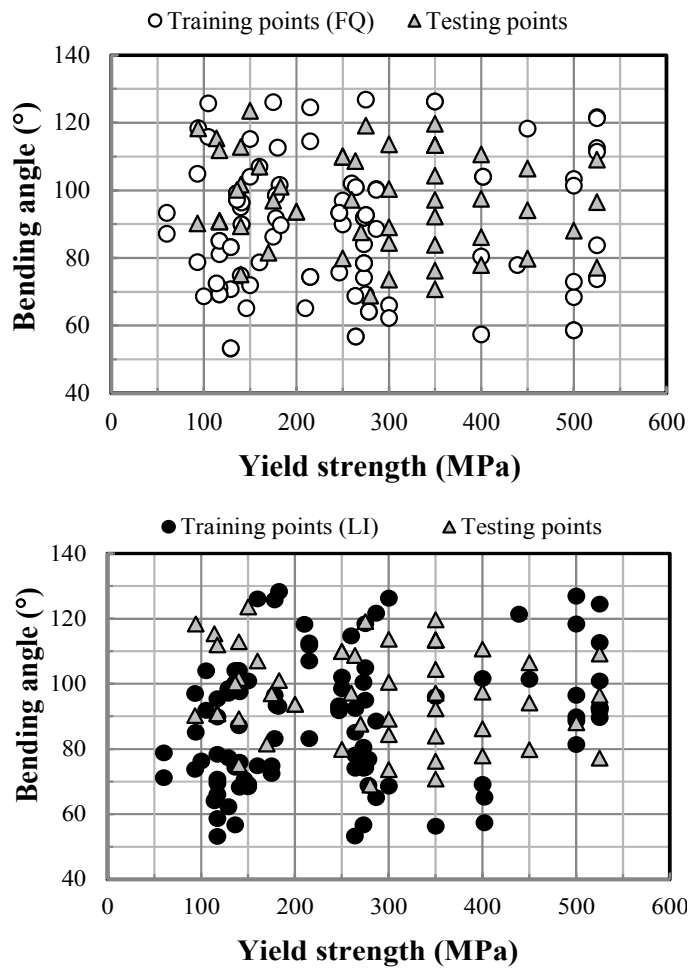

Fig. 3. The datasets based on (a) FQ and (b) LI models.

From the results in Table II, it can be observed that the model in which examples were selected based on the FQ model shows a higher correlation coefficient when compared with the model in which examples were selected based on the LI model. 
Finally, the model with examples selected based on the FQ model reached a significant level ( 0.0012 in the case of $\mathrm{P} 2 \mathrm{EXP})$, which is more reliable than the model based on the LI model ( 0.026 in the case of $\left.\mathrm{P} 2_{\mathrm{EXP}}\right)$. Therefore, the FQ model shows a better fit when compared to the LI model, and the $\mathrm{R}^{2}$ values for the full quadratic models are satisfactory.

TABLE II. COEFFICIENT OF DETERMINATION R ${ }^{2}$

\begin{tabular}{|c|c|c|}
\hline Model & LI & FQ \\
\hline $\mathrm{RSM}$ & 0.9165 & 0.9945 \\
\hline $\mathrm{P} 0_{\mathrm{EXP}}$ & 0.9694 & 0.9852 \\
\hline $\mathrm{P} 1_{\mathrm{EXP}}$ & 0.9696 & 0.9879 \\
\hline $\mathrm{P} 2_{\mathrm{EXP}}$ & 0.9740 & 0.9988 \\
\hline
\end{tabular}

Figure 4 shows the relationship between the normalized error and the metamodel type for both the fitted LI (Fig. 4a) and FQ (Fig. 4b) models. Fig. 4a refers to the NMAX and Fig. $4 \mathrm{~b}$ refers to the NRMSE. The accuracy of all of the kriging metamodels and the RSM model is greater in the case of selecting examples based on the FQ model than on the LI model. There are large differences in the normalized error between the FQ model and the LI model. From Fig. 4a, it can be observed that when selecting examples based on the FQ model the best model with the minimum NMAX is the $P_{2 E X P}$ followed by the RSM.
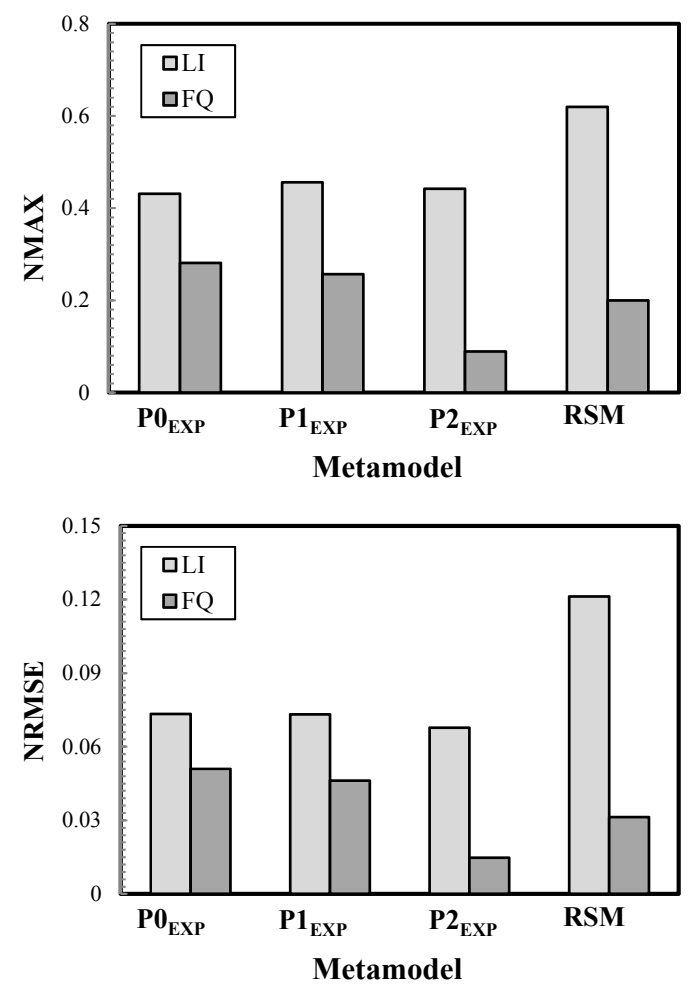

Fig. 4. The relationship between normalized error and metamodel type for both trained models.

Figure 5 shows the result of the metamodel-predicted springback angle versus the actual FEM. Fig. 5a, 5b and 5c refer to the KMM of $\mathrm{P} 0_{\mathrm{EXP}}, \mathrm{P} 1_{\mathrm{EXP}}$ and $\mathrm{P} 2_{\mathrm{EXP}}$, respectively. Fig.
$5 \mathrm{~d}$ refers to the RSM model. For accurate prediction, all of the points should lie on the $45^{\circ}$ line. In the case of $\mathrm{P} 0_{\mathrm{EXP}}$ and $\mathrm{P} 1_{\mathrm{EXP}}$, the prediction of the kriging metamodel is not accurate compared with $\mathrm{P} 2$ EXP and RSM, as shown in Figs. $5 \mathrm{c}$ and $5 \mathrm{~d}$.

In the case of RSM and $\mathrm{P}_{2 \mathrm{EXP}}$, all of the points are close to the $45^{\circ}$ line. The lines representing $\pm 5 \%$ accuracy are drawn to show the percentage error in the prediction. From Fig. $5 \mathrm{c}$, it can be observed that all of the predictions are within $\pm 5 \%$ accuracy. The maximum absolute error in the prediction of springback is $2.8 \%$. Fig. $5 \mathrm{~d}$ shows the best RSM predicted springback versus the simulated FEM prediction. It can be observed that out of 50 predictions, most of the predictions are within $\pm 5 \%$ accuracy; seven predictions are within $\pm 10 \%$ and one prediction is outside the $\pm 10 \%$ accuracy.
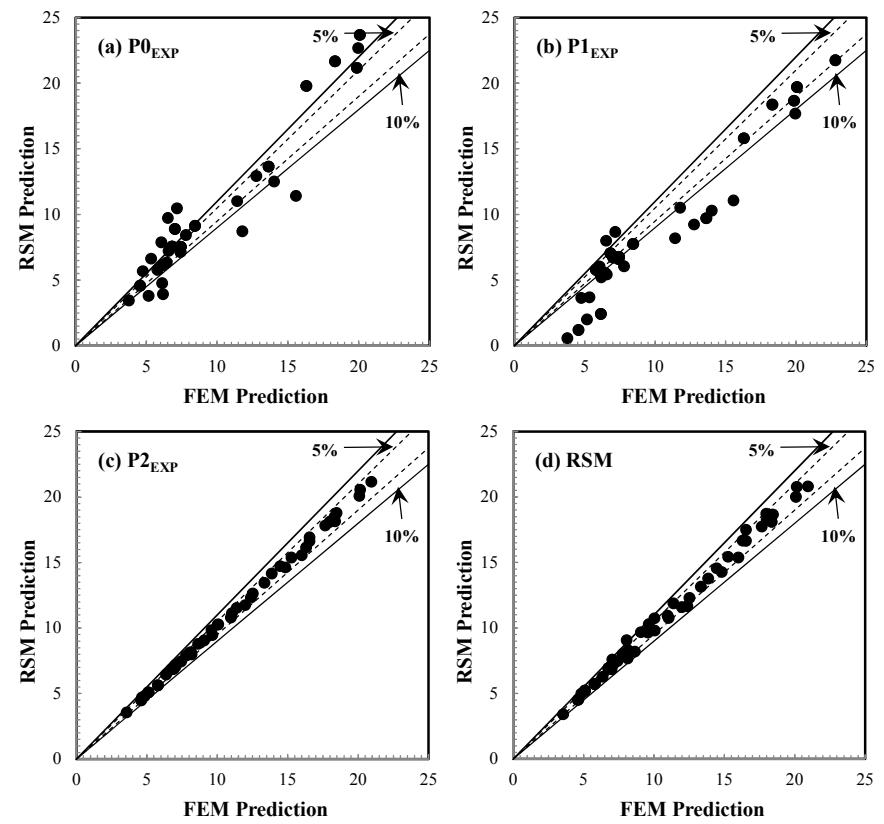

Fig. 5. The metamodel predicted springback angle versus simulated FEM results. The straight lines are confidence intervals (CIs).

\section{CONCLUSIONS}

In this study, the kriging metamodeling approach was implemented to predict the springback angle for the sheet metal air bending process. A comparative analysis of different metamodel schemes based on the kriging predictions has been conducted. On the basis of the computational results, the metamodels proposed avoid a great number of time-consuming evaluation processes and have significant merit in the aspect of accuracy. The kriging metamodels selected using a D-optimal design based on the full quadratic model are able to provide more accurate prediction of the springback than the metamodels based on the linear-interactions model. The kriging metamodel with a 2nd-order polynomial trend function and an exponential correlation function provides a minimal normalized error compared with alternative metamodels investigated in this paper; this error compares the prediction of the springback angle by the metamodels and the finite element simulation outputs. The springback angle of sheet-metal 
forming can be efficiently predicted using the kriging metamodel instead of the response surface methodology.

\section{REFERENCES}

[1] M. Osman, M. Shazly, A. El-Mokaddem, A. Wifi, "Springback prediction in V-die bending: modelling and experimentation", J. Achiev. Mater. Manufac. Eng., Vol. 38, pp. 179-186, 2010

[2] T. Botelho, E, Bayraktar, G. Inglebert, "Comparison of experimental and simulation results of 2D-draw-bend spring-back", J. Achiev. Mater. Manufac. Eng., Vol. 18, pp. 275-278, 2006

[3] I. Ragai, D. Lazim, J. Nemes, "Anisotropy and springback in drawbending of stainless steel 410: experimental and numerical study", J. Mater. Proc. Techno., Vol. 166, pp. 116-127, 2005

[4] M. Sitar, F. Kosel, M. Brojan, "Numerical and experimental analysis of elastic-plastic pure bending and springback of beams of asymmetric cross-sections", Int. J. Mech. Sci., Vol. 90, pp. 77-88, 2015

[5] F. Kosel, T. Videnic, T. Kosel, M. Brojan, "Elasto-plastic springback of beams subjected to repeated bending/unbending histories", J. Mater. Eng. Perform., Vol. 20, pp. 846-854, 2011

[6] Y. Zhu, Y. Liu, H. Yang, H. Li, "Improvement of the accuracy and the computational efficiency of the springback prediction model for the rotary-draw bending of rectangular H96 tube", Int. J. Mech. Sci., Vol. 66, pp. 224-232, 2012

[7] R. Kazan, M. Firat, A. Tiryaki, "Prediction of springback in wipebending process of sheet metal using neural network", Materials \& Design, Vol. 30, pp. 418-423, 2009

[8] A. Ghaei, "Numerical simulation of springback using an extended return mapping algorithm considering strain dependency of elastic modulus", Int. J. Mech. Sci., Vol. 65, pp. 38-47, 2012

[9] E. Nakamachi, T. Honda, H. Kuramae, Y. Morita, T. Ohata, H. Morimoto, "Two-scale finite element analyses for bendability and springback evaluation based on crystallographic homogenization method”, Int. J. Mech. Sci., Vol. 80, pp. 109-121, 2014

[10] H. Kim, N. Nargundkar, T. Altan, "Prediction of bend allowance and springback in air bending", J. Manufac. Sci. Eng., Vol. 129, pp. 342-351, 2006

[11] S. Panthi, N. Ramakrishnan, K. Pathak, J. Chouhan, "An analysis of springback in sheet metal bending using finite element method", J. Mater. Proc. Techno., Vol. 186, pp. 120-124, 2007

[12] I. Vladimirov, M. Nargundkar, S. Reese, "Prediction of springback in sheet forming by a new finite strain model with nonlinear kinematic and isotropic hardening", J. Mater. Proc. Techno., Vol. 209, pp. 4062-4075, 2009

[13] R. Srinivasan, D. Vasudevan, A. Padmanabhan, "Prediction of springback and bend force in air bending of electro-galvanised steel sheets using artificial neural networks", Aust. J. Mech. Eng., Vol. 12, pp. 25-37, 2014

[14] H. Baseri, B. Rahmani, Bakhshi-JM, "Predictive Models of the SpringBack in the Bending Process, Applied Artificial Intelligence", Appl. Artificial. Intell., Vol. 26, pp. 862-877, 2012

[15] L. Wang, G. Huang, H. Zhang, Y. Wang, L. Yin, "Evolution of springback and neutral layer of AZ31B magnesium alloy V-bending under warm forming conditions", J. Mater. Proc. Techno., Vol. 213, pp. 844-850, 2013

[16] D. Zhang, Z. Cui, X. Ruan, Y. Li, "An analytical model for predicting springback and side wall curl of sheet after U-bending", Compu. Mater. Sci., Vol. 38, pp. 707-715, 2007

[17] M. Firat, "U-Channel Forming Analysis with an Emphasis on Springback Deformation", Materials \& Design, Vol. 28, pp. 147-154, 2007

[18] P. Chen, M. Koç, "Simulation of springback variation in forming of advanced high strength steels", J. Mater. Proc. Techno., Vol. 190, pp. 189-198, 2007

[19] G. Sharad, V. Nandedkar, "Springback in Sheet Metal U Bending-FEA and Neural Network", Approach Procedia Mater. Sci. Vol. 6, pp. 835839,2014

[20] A. Mkaddem, D. Saidane, "Experimental approach and RSM procedure on the examination of springback in wiping-die bending processes", $\mathrm{J}$. Mater. Proc. Techno., Vol. 189, pp. 325-333, 2007

[21] T. Zou, J. Xin, D, Li, Q. Ren, "Analytical approach of springback of arced thin plates bending", Procedia Eng., Vol. 81, pp. 993-998, 2014
[22] S. Feifei, Y. He, L. Heng, Z. Mei, L. Guangjun, "Springback prediction of thick-walled high-strength titanium tube bending", Chinese J. Aeronautics, Vol. 26, pp. 1336-1345, 2013

[23] X. Yang, C. Choi, N. Sever, T. Altan, "Prediction of springback in airbending of Advanced High Strength steel (DP780) considering Young's modulus variation and with a piecewise hardening function", Int. J. Mech. Sci., Vol. 105, pp. 266-272, 2016

[24] J. Lee, F. Barlat, M. Lee, "Constitutive and friction modeling for accurate springback analysis of advanced high strength steel sheets", Int. J. Plasticity, Vol. 71, pp. 113-135, 2015

[25] M. Tisza, Z. Lukacs, "Springback analysis of high strength dual-phase steels", Procedia Eng., Vol. 81, pp. 975-980, 2014

[26] S. Panthi, N. Ramakrishnan, "Semi analytical modeling of springback in arc bending and effect of forming load", Trans. Nonferrous Met. Soc. China, Vol. 21, pp. 2276-2284, 2011

[27] N. Nanu, G. Brabie, "Analytical model for prediction of springback parameters in the case of $U$ stretch-bending process as a function of stresses distribution in the sheet thickness", Int. J. Mech. Sci., Vol. 64, pp. 11-21, 2012

[28] X. Xue, J. Liao, G. Vincze, J. Gracio, "Modelling of mandrel rotary draw bending for accurate twist springback prediction of an asymmetric thinwalled tube", J. Mater. Proc. Techno., Vol. 216, pp. 405-417, 2015

[29] M. Lee, J. Kim, K. Chung, S. Kim, R. Wagoner, H. Kim, "Analytical springback model for lightweight hexagonal close-packed sheet metal", Int. J. Plasticity, Vol. 25, pp. 399-419, 2009

[30] V. Esat, H. Darendeliler, M. Gokler, "Finite element analysis of springback in bending of aluminium sheets", Materials \& Design, Vol 23 , pp. 223-229, 2002

[31] S. Lee, D. Yang, "An assessment of numerical parameters influencing springback in explicit finite element analysis of sheet metal forming process", J. Mater. Proc. Techno., Vol. 80, pp. 60-67, 1998

[32] K. Li, W. Carden, R. Wagoner, "Simulation of springback", Int. J. Mech. Sci., Vol. 44, pp. 103-122, 2002

[33] L. De-Vin, "Curvature prediction in air bending of metal sheet", J. Mater. Proc. Techno., Vol. 100, pp. 257-261, 2000

[34] C. Díaz, M. Victoria, O. Querin, P. Martí, "Optimum design of semirigid connections using metamodels", J. Constructional Steel Res., Vol. 78, pp. $97-106,2012$

[35] A. Khuri, J. Cornell, Response Surfaces: designs and analyses, 2nd ed. New York ISBN 0-8247-9781-8, 1996

[36] D. Allaix, V. Carbone, "An improvement of the response surface method", Structural Safety, Vol. 33, pp. 165-172, 2011

[37] A. Taflanidis, "Stochastic subset optimization incorporating moving least squares response surface methodologies for stochastic sampling", Adv. Eng. Soft., Vol. 44, pp. 3-14, 2012

[38] F. Abu-Khadra, J. Abu-Qudeiri, "Comparison between neural network and response surface metamodels based on D-optimal designs", Int. J. Compu. Mater. Sci. Sur. Eng., Vol. 5, pp. 85-101, 2013

[39] M. Ali-Tavoli, N. Nariman, A. Khakhali, "Multi-objective optimization of abrasive flow machining processes using polynomial neural networks and genetic algorithms", Mach. Sci. Techno., Vol. 10, pp. 491-510, 2006

[40] M. Naseri, F. Othman, "Determination of the length of hydraulic jumps using artificial neural networks", Adv. Eng. Soft., Vol. 48, pp. 27-31, 2012

[41] V. Papadopoulos, D. Giovanis, N. Lagaros, M. Papadrakakis, "Accelerated subset simulation with neural networks for reliability analysis", Compu. Meth. Appl. Mech. Eng. Vol. 223, pp. 70-80, 2012

[42] R. Narayanasamy, P. Padmanabhan, "Comparison of regression and artificial neural network model for the prediction of springback during air bending process of interstitial free steel sheet", J. Intelligent Manufacturing, Vol. 23, pp. 357-364, 2012

[43] H. Sun, M. Schafer, "Reduced order model assisted evolutionary algorithms for multi-objective flow design optimization", Engineering Optimization, Vol. 43, pp. 97-114, 2011

[44] F. Magoules, L. Diago, I. Hagiwara, "Efficient preconditioning for image reconstruction with radial basis functions", Adv. Eng. Soft., Vol. 38, pp. $320-327,2007$

[45] H. Safikhani, A. Khalkhali, M. Farajpoor, "Pareto based multi-objective optimization of centrifugal pumps using CFD, neural networks and genetic algorithms", Engineering Applications of Computational Fluid Mechanics, Vol. 5, pp. 37-48, 2011 
[46] J. C. Kleijnen, Design and Analysis of Simulation Experiments; 2nd ed. Springer, 2015.

[47] N. Cressie, "The Origins of Kriging", Math. Geo., Vol. 22, pp. 239-252, 1990.

[48] B. Echard, N. Gayton, M. Lemaire, "AK-MCS an active learning reliability method combining Kriging and Monte Carlo Simulation", Structural Safety, Vol. 33, pp. 145-154, 2011

[49] B. Echard, N. Gayton, M. Lemaire, N. Relun, "A combined importance sampling and Kriging reliability method for small failure probabilities with time-demanding numerical models", Reliab. Eng. Sys. Saf., Vol. 111, pp. 232-240, 2013
[50] Z. Fu, M. Jianhua, "Springback prediction of high-strength sheet metal under air bending forming and tool design based on GA-BPNN", Int. J. Adv. Manufac. Techno., Vol. 53, pp. 473-483, 2011

[51] S. Chen, X. Hong, C. Harris, "Regression based D-optimality experimental design for sparse kernel density estimation", Neurocomputing, Vol. 73, pp. 727-739, 2010 